\title{
Cancers Attributable to Alcohol Consumption in Nigeria: 2012-2014
}

OPEN ACCESS

Edited by:

Maria Paula Curado,

International Prevention

Research Institute, France

Reviewed by:

Alireza Sadjadi,

Tehran University of Medical

Sciences, Iran

Saima Wajid,

Jamia Hamdard University,

India

*Correspondence:

Clement A. Adebamowo cadebamowo@ihv.umaryland.edu

†These authors have contributed equally to this work.

Specialty section:

This article was submitted to Cancer Epidemiology and Prevention, a section of the journal Frontiers in Oncology

Received: 12 May 2017 Accepted: 08 August 2017 Published: 24 August 2017

Citation:

Odutola MK, Jedy-Agba EE Dareng EO, Adebamowo SN,

Oga EA, Igbinoba F, Otu T, Ezeome E, Hassan $R$ and Adebamowo CA

(2017) Cancers Attributable

to Alcohol Consumption

in Nigeria: 2012-2014.

Front. Oncol. 7:183.

doi: 10.3389/fonc.2017.00183

\begin{abstract}
Michael Kolawole Odutola ${ }^{1 \dagger}$, Elima E. Jedy-Agba ${ }^{1,2 t}$, Eileen O. Dareng ${ }^{3}$, Sally N. Adebamowo ${ }^{4}$, Emmanuel A. Oga ${ }^{5}$, Festus Igbinoba ${ }^{6}$, Theresa Otu ${ }^{7}$, Emmanuel Ezeome ${ }^{8}$, Ramatu Hassan ${ }^{9}$ and Clement A. Adebamowo ${ }^{1,4,10 *}$
\end{abstract}

${ }^{1}$ Institute of Human Virology, Abuja, Nigeria, ${ }^{2}$ Department of Non-communicable Disease Epidemiology, London School of Hygiene and Tropical Medicine, London, United Kingdom, ${ }^{3}$ Center for Cancer Genetic Epidemiology, Department of Public Health and Primary Care, University of Cambridge, Cambridge, United Kingdom, ${ }^{4}$ Department of Epidemiology and Public Health, Marlene and Stewart Greenebaum Comprehensive Cancer Center, University of Maryland School of Medicine, Baltimore, MD, United States, ${ }^{5}$ Battelle Memorial Institute, Baltimore, MD, United States, ${ }^{6}$ National Hospital Abuja, Abuja, Nigeria, ${ }^{7}$ University of Abuja Teaching Hospital, Gwagwalada, Nigeria, ${ }^{8}$ University of Nigeria Teaching Hospital, Enugu, Nigeria, ${ }^{9} \mathrm{Federal}$ Ministry of Health, Abuja, Nigeria, ${ }^{10}$ Institute of Human Virology, University of Maryland School of Medicine, Baltimore, MD, United States

Introduction: Alcohol consumption has been identified as a risk factor for many cancers but less attention has been paid to the fraction of those cancers that are attributable to alcohol consumption. In this study, we evaluated the incidence and population attributable fraction (PAF) of cancers associated with alcohol consumption in Nigeria.

Methods: We obtained data on incidence of cancers from two population-based cancer registries (PBCRs) in Nigeria and identified cancer sites for which there is strong evidence of an association with alcohol consumption based on the International Agency for Research on Cancer Monograph 100E. We computed the PAF for each cancer site by age and sex, using prevalence and relative risk estimates from previous studies.

Results: Between 2012 and 2014 study period, the PBCRs reported 4,336 cancer cases of which 1,627 occurred in males, and 2,709 occurred in females. Of these, a total of 1,808 cancer cases, 339 in males and 1,469 in females, were associated with alcohol intake. The age standardized incidence rate (ASR) of alcohol associated cancers was 77.3 per 100,000 . Only $4.3 \%(186 / 4,336)$ of all cancer cases or $10.3 \%(186 / 1,808)$ of alcohol associated cancers were attributable to alcohol consumption. Some $42.5 \%$ (79/186) of these cancers occurred in males while $57.5 \%$ (107/186) occurred in females. The ASR of cancers attributable to alcohol in this population was 7.2 per 100,000 . The commonest cancers attributable to alcohol consumption were cancers of the oral cavity and pharynx in men and cancer of the breast in women.

Conclusion: Our study shows that $4.3 \%$ of incident cancers in Nigeria can be prevented by avoiding alcohol consumption. While the incidence of cancers associated with alcohol intake is high, the proportion attributable to alcohol consumption is much lower suggesting that the number of cancers that may be prevented by eliminating alcohol intake in this population is relatively low.

Keywords: cancer, alcohol, associated cancers, attributable cancers, cancer registry, Nigeria 


\section{INTRODUCTION}

Alcohol consumption is a major risk factor for morbidity, disability, and mortality worldwide (1). In 2012, an estimated 3.3 million deaths (5.9\% of all global deaths) were attributable to alcohol consumption, mainly from cardiovascular diseases, injuries, gastrointestinal illnesses, and cancer (2). According to the 2014 World Health Organization (WHO) Global Status Report on Alcohol and Health, 38.1\% of the world's population aged 15 years or older were estimated to be regular drinkers, with an average consumption of $38.6 \mathrm{~g}$ of pure alcohol per day (approximately 2.8 standard servings of alcoholic drinks) $(2,3)$.

There is considerable variation in the prevalence of drinking across the world, but the burden of disease and death remains significant in most countries (4). According to the WHO, in 2014, Nigeria was the fourth leading African country in alcohol consumption after South Africa, Namibia, and Gabon (2). The average national adult per capita consumption of alcohol between 2008 and 2010 in Nigeria was 10.1 1/year which is similar to that of the United States (9.8 1/year), but higher than that reported in China (6.7 1/year) (2).

The International Agency for Research on Cancer (IARC) and World Cancer Research Fund have concluded that there is strong evidence for a causal relationship between alcohol consumption and cancers of the oral cavity, pharynx, esophagus, colon, rectum, liver, gall bladder, pancreas, larynx, and breast $(5,6)$. According to IARC, 770,000 (5.5\%) of the 14.1 million new cancer cases reported worldwide in 2012 were attributable to alcohol consumption (4, 7 ). In contrast, consumption of mild to moderate quantities of alcohol has an inverse association with risk of thyroid cancer (8).

The proportion of incident cancer cases and cancer deaths attributable to alcohol consumption varies across the world. In the African region, it is estimated that $4.8 \%$ of cancer cases were attributable to alcohol consumption in 2012, while in the American and European regions, 4.2 and 5.4\% of cancer cases were attributable to alcohol consumption, respectively (4). Although country-specific estimates of cancers attributable to alcohol consumption are available for countries like Korea (2.0\%), Australia (2.8\%), United States (3.0\%), United Kingdom (3.6\%), and China $(4.4 \%)$, there are no country-specific estimates of cancers attributable to alcohol consumption in Nigeria or other African countries (9-13).

With increasing economic development and disposable income, consumption of alcohol in many African countries is rising. It is therefore important to estimate the current burden of alcohol associated and alcohol attributable cancers in Nigeria in order to ascertain the impact of secular changes in alcohol consumption and the proportion of cancers that would be eliminated by reducing or prohibiting alcohol intake in this population. This would be helpful in guiding public health policies geared toward cancer prevention and control.

\section{MATERIALS AND METHODS}

\section{Data Sources}

We obtained data on all incident cancer cases from 2012 to 2014 reported by two population-based cancer registries (PBCRs), the Abuja, and Enugu cancer registry (ECR) in Nigeria. The
Abuja cancer registry (ABCR) is located in Abuja, the capital of Nigeria which is centrally located and home to people of varied ethnic groups and religions. ABCR was established in 2009 and its catchment area covers the entire federal capital territory which has a population of $1,406,239$ people (14). The ECR is located in Enugu in the southeastern region of Nigeria. ECR was established in 2012, and covers a defined population of 1,103,153 people (14). The two PBCRs use the International Classification of Disease for Oncology, 3rd Edition (ICD-O3) for coding and classification of cancers. ABCR uses CanReg4 for data entry, processing, and storage, while ECR uses CanReg5 software. Data from the two registries analyzed in this study are based on de-identified data as is the international practice in cancer registration.

\section{Data Handling and Statistical Analysis}

We performed data quality control checks to remove duplicates and to ensure logical correctness and overall accuracy of the data. Analysis of incident cancer cases and age standardized incidence rate (ASR) calculation was generated by the CanReg5 software. We identified cancer sites for which there is strong evidence of an association with alcohol consumption based on the IARC Monograph 100E (5). The cancer sites (ICD-O code) considered in this study were: oral cavity and pharynx (C00-C14), esophagus (C15), colorectal (C18-C20), liver (C22), thyroid (C73), gall bladder (C23-C24), pancreas (C25), and larynx (C32) in both sexes; and breast (C50) in females (Table 1). We obtained age and sex-specific estimates of the number of new cancer cases reported by the individual registries from their cancer registry databases for the time period under review (Table 1).

We used the population attributable fraction (PAF) computed for each cancer site by age and sex category from the formula (15):

$$
\sum \frac{(P *(\mathrm{RR}-1)}{(P *(\mathrm{RR}-1)+1)}
$$

where RR represents the relative risk of alcohol consumption, and $P$ is the proportion of people who consume alcohol in the population. This method has been used in similar studies to estimate the number of cancers attributable to alcohol consumption (9-13).

For this study, we used the PAF for alcohol consumption associated with cancers derived from prevalence and relative risk estimates worldwide (Table 2) (4). We did not use PAF from Nigeria because there were no relative risks for different categories of alcohol consumption (light drinkers $\leq 1 \mathrm{drink} /$ day, moderate 2-3 drinks/day, and heavy drinkers $>4$ drinks/day) in our population. We calculated the numbers of cancer cases attributable to alcohol consumption in each sex by multiplying the PAF of each cancer site with the overall numbers of cancer cases reported per cancer site according to the formula (15):

$$
\mathrm{ACalc}=\sum(\mathrm{PAF} * N)
$$

where $N$ represents the number of alcohol associated cancers per cancer site reported by the PBCRs. We carried out sensitivity analyses for cancers attributable to alcohol, using GLOBOCAN 2012 database for Nigeria (Table 2). The GLOBOCAN is a data source from IARC on estimated cancer incidence, mortality, and 
TABLE 1 | Population attributable fraction (PAF) and estimated numbers of cancers attributable to alcohol consumption in Nigeria from 2012 to 2014.

\begin{tabular}{|c|c|c|c|c|c|c|c|}
\hline Cancer site & ICD-O3 code & No. of cancer cases & $\begin{array}{l}\% \text { of alcohol associated } \\
\text { cancers }\end{array}$ & ASR & PAF $\%$ & $\begin{array}{l}\text { Cancer cases attributable to } \\
\text { alcohol }\end{array}$ & ASR \\
\hline \multicolumn{8}{|l|}{ Male } \\
\hline Oral cavity and pharynx & $\mathrm{C} 00-\mathrm{C} 14$ & 79 & 4.4 & 4.2 & 44.7 & 36 & 1.5 \\
\hline Esophagus & C15 & 12 & 0.7 & 0.6 & 51.8 & 6 & 0.3 \\
\hline Colorectal & C18-C20 & 107 & 5.9 & 5.1 & 15.0 & 16 & 1.0 \\
\hline Liver & $\mathrm{C} 22$ & 93 & 5.1 & 4.0 & 13.0 & 12 & 0.5 \\
\hline Gall bladder & C23-C24 & 3 & 0.2 & 0.2 & 25.3 & 1 & 0.1 \\
\hline Pancreas & $\mathrm{C} 25$ & 19 & 1.1 & 1.0 & 5.4 & 1 & 0.1 \\
\hline Larynx & C32 & 26 & 1.4 & 1.1 & 28.4 & 7 & 0.3 \\
\hline Total cancers in males (\%) & & $339(20.8)$ & 18.8 & 16.2 & & 79 (4.9) & 4.3 \\
\hline \multicolumn{8}{|l|}{ Female } \\
\hline Oral cavity and pharynx & $\mathrm{C} 00-\mathrm{C} 14$ & 57 & 3.1 & 5.0 & 17.2 & 10 & 1.0 \\
\hline Esophagus & C15 & 7 & 0.4 & 0.5 & 28.3 & 2 & 0.1 \\
\hline Colorectal & $\mathrm{C} 18-\mathrm{C} 20$ & 97 & 5.4 & 7.0 & 2.3 & 2 & 0.1 \\
\hline Liver & $\mathrm{C} 22$ & 52 & 2.9 & 2.7 & 12.8 & 7 & 0.4 \\
\hline Gall bladder & $\mathrm{C} 23-\mathrm{C} 24$ & 4 & 0.2 & 0.3 & 8.2 & 0 & 0.0 \\
\hline Pancreas & $\mathrm{C} 25$ & 27 & 1.5 & 2.0 & 1.4 & 0 & 0.0 \\
\hline Larynx & C32 & 8 & 0.4 & 0.6 & 9.7 & 1 & 0.1 \\
\hline Breast & C50 & 1,217 & 67.3 & 60.1 & 7.3 & 85 & 4.2 \\
\hline Total cancers in females (\%) & & $1,469(54.2)$ & 81.2 & 78.2 & & $107(3.9)$ & 5.9 \\
\hline Total cancers in both sexes (\%) & & $1,808(41.7)$ & 41.7 & 77.3 & & $186(4.3)$ & 7.2 \\
\hline
\end{tabular}

TABLE 2 | Sensitivity analyses of cancers attributable to alcohol consumption in Nigeria from GLOBOCAN 2012 database.

\begin{tabular}{|c|c|c|c|c|c|c|}
\hline Cancer site & ICD-O3 code & No. of cancer cases & ASR & PAF $\%$ & Cancer cases attributable to alcohol & ASR \\
\hline \multicolumn{7}{|l|}{ Male } \\
\hline Oral cavity and pharynx & $\mathrm{C} 00-\mathrm{C} 14$ & 1,441 & 10.4 & 44.7 & 648 & 4.7 \\
\hline Esophagus & C15 & 145 & 9.0 & 51.8 & 75 & 4.7 \\
\hline Colorectal & C18-C20 & 2,164 & 20.6 & 15.0 & 325 & 3.1 \\
\hline Liver & $\mathrm{C} 22$ & 7,875 & 15.3 & 13.0 & 1,024 & 2.0 \\
\hline Gall bladder & C23-C24 & 90 & 2.1 & 25.3 & 23 & 0.5 \\
\hline Pancreas & $\mathrm{C} 25$ & 935 & 4.9 & 5.4 & 47 & 0.2 \\
\hline Larynx & C32 & 732 & 3.9 & 28.4 & 205 & 1.1 \\
\hline Total cancers in males (\%) & & $13,382(35.8)$ & 66.2 & & $2,347(6.3)$ & 16.3 \\
\hline \multicolumn{7}{|l|}{ Female } \\
\hline Oral cavity and pharynx & $\mathrm{C} 00-\mathrm{C} 14$ & 1081 & 4.0 & 36.7 & 400 & 1.5 \\
\hline Esophagus & C15 & 141 & 3.1 & 44.7 & 63 & 1.4 \\
\hline Colorectal & C18-C20 & 2,008 & 14.3 & 9.2 & 181 & 1.3 \\
\hline Liver & $\mathrm{C} 22$ & 4,172 & 5.3 & 12.9 & 542 & 0.7 \\
\hline Gall bladder & C23-C24 & 88 & 2.3 & 15.6 & 14 & 0.4 \\
\hline Pancreas & $\mathrm{C} 25$ & 738 & 3.6 & 3.5 & 30 & 0.1 \\
\hline Larynx & C32 & 59 & 0.5 & 26.1 & 15 & 0.1 \\
\hline Breast & C50 & 27,304 & 43.1 & 7.3 & 1,911 & 3.0 \\
\hline Total cancers in females (\%) & & $35,591(55.0)$ & 76.2 & & $3,156(4.9)$ & 8.5 \\
\hline Total cancers in both sexes (\%) & & $48,973(48.0)$ & 92.8 & & $5,503(5.4)$ & 13.9 \\
\hline
\end{tabular}

prevalence for 184 countries of the world including Nigeria in 2012. GLOBOCAN 2012 estimated cancer incidence in Nigeria by using regional incidence rates to estimate the weighted average of local incidence rates from three cancer registries in Nigeria (Abuja, Ibadan, and Enugu) for the time period 2006-2011 (16).

\section{Ethics}

The Nigerian National Health Research Ethics Committee determined that cancer registration activities are exempt from review and informed consent from participants is not required because researchers do not access identifiable patient information (17). We used de-identified data for our study and did not have access to participants' personal health information.

\section{RESULTS}

The two PBCRs reported 4,336 new cancer cases from 2012 to 2014 (ASR 113.9 per 100,000) of which 1,627 (37.5\%; ASR 82.0 per 100,000) occurred in males while 2,709 (62.5\%; ASR 145.9 per 100,000$)$ occurred in females. Of these, $1,808(41.7 \%)$ were alcohol associated with an ASR of 77.3 per 100,000 . Some $81.3 \%$ $(1,469$ of 1,808 ; ASR 78.2 per 100,000) of the alcohol associated cancers occurred in females while $18.8 \%$ (339 of 1,808; ASR 16.2 per 100,000) occurred in males (Table 1).

Overall, only $4.3 \%$ (186 of 4,336 ; ASR 7.2 per 100,000 ) of the cancers were attributable to alcohol consumption. Most of the cancers attributable to alcohol $(2.5 \% ; 107 / 4336$; ASR 5.9 per 
$100,000)$ occurred in women and (1.8\%; 79/4336; ASR 4.3 per $100,000)$ occurred in men.

\section{Oral Cavity and Pharyngeal Cancer}

The PBCRs reported 136 oral cavity and pharyngeal cancers from 2012 to 2014 (ASR 4.6 per 100,000). Of these, 79 (58.1\%; ASR 4.2 per 100,000$)$ cases occurred in males and 57 (41.9\%; 5.0 per $100,000)$ cases occurred in females. Using the PAF estimates of $44.7 \%$ in males and $17.2 \%$ in females (4), we computed that $33.8 \%$ (46/136; ASR of 1.5 per 100,000) of these cancers were attributable to alcohol consumption (Table 1). The ASR for cancers of the oral cavity and pharynx attributable to alcohol consumption were 1.5 per 100,000 in males and 1.0 per 100,000 in females (Figure 1).

\section{Esophageal Cancer}

There were 19 esophageal cancer cases in both sexes from 2012 to 2014 (ASR 0.6 per 100,000), of which 12 (63.2\%; ASR 0.6 per $100,000)$ occurred in males while 7 (36.8\%; ASR 0.5 per 100,000$)$ occurred in females. We calculated the alcohol attributable fraction for cancer of the esophagus using PAF estimates of $51.8 \%$ in males and $28.3 \%$ in females and found that $42.1 \%$ (8/19; ASR 0.2 per 100,000$)$ of the esophageal cancers in both sexes were attributable to alcohol consumption (Table 1) (4). The ASR for esophageal cancers attributable to alcohol was 0.3 per 100,000 in males and 0.1 per 100,000 in females (Figure 1).

\section{Colorectal Cancer}

A total of 204 colorectal cancer cases were reported in both sexes from 2012 to 2014 by ABCR and ECR (ASR 6.1 per 100,000). Colorectal cancer was the most common alcohol associated cancer in males, representing 5.9\% (107/1,808; ASR 5.1 per $100,000)$ of male cancers and the second most common alcohol associated cancer in females constituting 5.4\% (97/1,808; ASR 7.0 per 100,000$)$ female cancers. Using the PAF estimates of $15.0 \%$ in males and $2.3 \%$ in females (4), 8.8\% (18/204; ASR 0.6 per
$100,000)$ of colorectal cancer cases were attributable to alcohol consumption (Table 1). The ASR for colorectal cancers attributable to alcohol was 1.0 per 100,000 in males and 0.1 per 100,000 in females (Figure 1).

\section{Liver Cancer}

The registries reported 145 liver cancer cases (ASR 3.4 per $100,000)$ with 93 (64.1\%; ASR 4.0 per 100,000$)$ cases in males and 52 (35.9\%; ASR 2.7 per 100,000) cases in females. Using a PAF estimates of $13.0 \%$ in males and $12.8 \%$ in females (4), we computed that 19 of the 145 liver cancer cases (13.1\%; ASR 0.5 per 100,000) were attributable to alcohol consumption (Table 1). The ASR for liver cancers attributable to alcohol consumption was 0.5 per 100,000 in males and 0.4 per 100,000 in females (Figure 1).

\section{Gall Bladder Cancer}

We found seven gall bladder cancer cases from 2012 to 2014 (ASR 0.3 per 100,000$)$ in the PBCRs data. Of these, three cases $(42.9 \%$; ASR 0.2 per 100,000$)$ occurred in males and four cases $(57.1 \%$; ASR 0.3 per 100,000$)$ occurred in females. With a PAF estimates of $25.3 \%$ in males and $8.2 \%$ in females (4), we computed that one of the seven gall bladder cancer cases in males (14.3\%; ASR 0.1 per 100,000) was attributable to alcohol consumption (Table 1). There was no gall bladder cancer case attributable to alcohol consumption in females.

\section{Pancreatic Cancer}

The PBCRs reported 46 cases of pancreatic cancers in the study period (ASR 1.5 per 100,000$)$ of which $19(41.3 \% ; 1.0$ per 100,000$)$ cases occurred in males while 27 (58.7\%; 2.0 per 100,000$)$ cases occurred in females. Using a PAF estimates of $5.4 \%$ in males and $1.4 \%$ in females (4), we estimated that 1 of the 46 pancreatic cancer cases in males (2.2\%; ASR 0.1 per 100,000$)$ was attributable to alcohol consumption (Table 1). There was no pancreatic cancer case attributable to alcohol consumption in females.

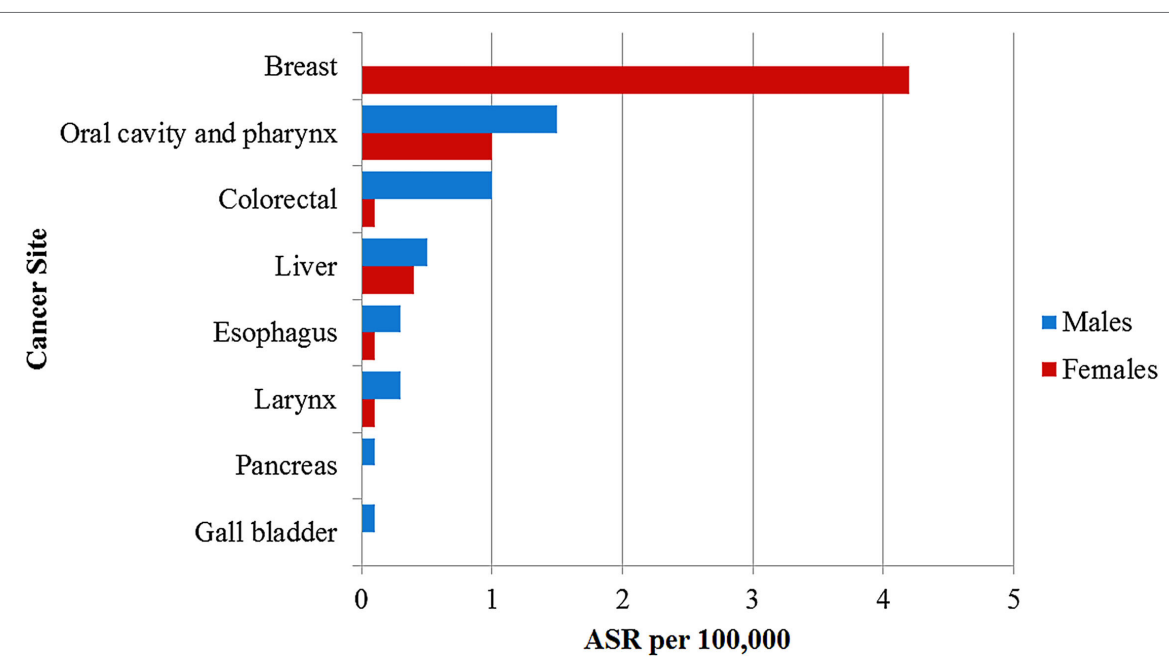

FIGURE 1 | Age standardized incidence rate per 100,000 of cancers attributable to alcohol consumption in Nigeria reported by the population-based cancer registries. 


\section{Laryngeal Cancer}

Some 34 laryngeal cancer cases were reported by ABCR and ECR within the study period (ASR 0.9 per 100,000). Of these, 26 (76.5\%; ASR 1.1 per 100,000$)$ cases occurred in males and 8 (23.5\%; ASR 0.6 per 100,000$)$ cases occurred in females. In our study, we calculated the alcohol attributable fraction for cancer of the larynx using a PAF estimates of $28.4 \%$ in males and $9.7 \%$ in females (4). We computed that $23.5 \%$ (8/34; ASR 0.2 per 100,000) of these cancers were attributable to alcohol consumption (Table 1). The ASR for laryngeal cancers attributable to alcohol was 0.3 per 100,000 in males and 0.1 per 100,000 in females (Figure 1).

\section{Breast Cancer}

Breast cancer was the commonest alcohol associated cancer reported during the study period. A total of 1,217 cases were reported in females with ASR 60.1 per 100,000, representing $28.1 \%(1,217 / 4,336)$ of all new cancers reported by the registries from 2012 to 2014 . Using a PAF estimates of $7.3 \%$ (4), we estimated that 2.0\% (85/4,336; ASR 4.2 per 100,000) of breast cancer cases reported within the study period were attributable to alcohol consumption (Table 1). There was no breast cancer case attributable to alcohol consumption in males.

\section{Thyroid Cancer}

The PBCRs reported 44 cases of thyroid cancers in both sexes from 2012 to 2014. Of these, 9 (20.5\%) cases occurred in males, while $35(79.5 \%)$ cases occurred in females. The combined ASR for thyroid cancers was 1.2 per 100,000; ASR for males was 0.4 per 100,000 and 2.0 per 100,000 for females. To determine how much more cancers of the thyroid there may have been if the people stop taking alcohol, we computed the association between mild to moderate alcohol intake and reduced risk of thyroid cancer using a relative risk of 0.74 from meta-analyses studies (18). We estimated that 60 cases of thyroid cancers with ASR 1.6 per 100,000 in both sexes (ASR 0.5 per 100,000 for males and 2.6 per 100,000 for females), would have occurred if alcohol was not consumed.

\section{Sensitivity Analyses}

In GLOBOCAN 2012, it was estimated that 102,079 cancer cases occurred in Nigeria [37,370 (36.6\%) in males and 64,709 (63.3\%) in females]. Of these, a total of 48,973 (48.0\%; ASR 92.8 per 100,000$)$ cancer cases, $27.3 \%(13,382 / 48,973)$ in males and $72.7 \%(35,591 / 48,973)$ in females, were associated with alcohol consumption. Of all incident cancers reported by GLOBOCAN, 5.4\% (5,503/102,079; ASR 13.9 per 100,000) were attributable to alcohol consumption $[2,347(6.3 \%)$ in males, $3,156(4.9 \%)$ in females] (Table 2).

In both data sources, the most common cancer attributable to alcohol consumption was breast cancer which accounted for approximately $2.0 \%$ of all cancer cases ( 85 of 4,336 in data from Nigeria PBCRs and 1,911 of 102,079 in data from GLOBOCAN 2012).

\section{DISCUSSION}

This is the first study to our knowledge, to report on the burden of cancers attributable to alcohol consumption in Africa. In this study, we estimated that $4.3 \%$ of all cancer cases in both sexes, $4.9 \%$ in men and $3.9 \%$ in women were attributable to alcohol consumption. The cancers with incidence most impacted by alcohol consumption were cancers of the oral cavity and pharynx in men (ASR 1.5 per 100,000) and cancer of the breast in women (ASR 4.2 per 100,000$)$. It is noteworthy that among women in our study, $80 \%(85 / 107)$ of all cancers attributable to alcohol consumption occurred in the breast.

The consumption of alcohol in Nigeria varies significantly by gender and age. Other factors such as religious and cultural norms influence the consumption of alcohol (19). However, with socioeconomic development, the volume and types of alcohol being consumed in the country has been increasing (19). According to the WHO, Nigeria ranks 27th worldwide in volume of alcohol in liters, consumed per capita per year, and it is the fourth leading country in alcohol consumption in Africa (2).

Alcohol consumption has been linked to the development of cancers of the oral cavity, pharynx, larynx, esophagus, liver, colon, rectum, and breast $(1,13)$. A recent review by the International Head and Neck Cancer Epidemiology consortium reports a multiplicative effect on the risk of oral and pharyngeal cancers (OPC) in people who smoke and drink alcohol (20). Other risk factors for OPC include oral sex and human papilloma virus infection (21).

Esophageal cancer is one of the most common cancers in East and Southern Africa (22), but it is less common in West Africa (23) and remains rare in Nigeria (24). Studies done to find out the reason for this uneven distribution across sub-Saharan Africa (SSA) regions have been inconclusive $(25,26)$. It has been suggested that these regional differences may be due to differences in risk factor profiles across SSA (27). Some studies have shown that unlike the Western African population, more people in the Eastern Africa consume locally brewed spirits or beer, and the peculiar process of brewing the drinks could predispose consumers to esophageal cancer $(25,28)$. The synergistic effect of heavy alcohol consumption and smoking habits which is a risk factor of esophageal cancer could be a potential factor for the disparities in incidence of esophageal cancer in the Eastern and Western Africa (25). Other studies have suggested that gene environmental interactions could contribute to increased risk of esophageal cancer in different regions $(29,30)$.

In Nigeria, colorectal cancer is one of the most common cancers in both sexes (31). It disproportionately affects men in Nigeria (31) and worldwide (32). Colorectal cancer was the most common alcohol associated cancer in males and the second most common in females in this study and the ASRs are similar to rates reported in Southern Africa but higher than in East and Central Africa (33). The WHO Status Report on Alcohol reveals that there has been a significant steep rise in alcohol consumption in Nigeria over the past 15 years, with increase in wine consumption, slight increase in beer consumption, while spirit consumption has remained the same. These could have contributed to the rising incidence of colorectal cancer in this population $(2,34)$. Other risk factors for colorectal cancer include dietary and lifestyle changes such as consumption of processed meat, smoking, and genetic predisposition $(31,35)$. Exposure of colon mucosa to acetaldehyde from microbial metabolism of ethanol in alcoholic 
drinks has been postulated as a mechanism for increasing the risk of developing colorectal cancer (36).

Liver cancer is the third commonest cancer in Nigerian men after prostate and colorectal cancers (31), and is a common cancer in other parts of West Africa $(37,38)$. It contributed to approximately one-third of all alcohol associated cancers in men in this study. Its risk factors include long-term alcohol use, cigarette smoking, dietary aflatoxins, and Hepatitis $\mathrm{B}$ and $\mathrm{C}$ virus infections $(39,40)$. It has been estimated that $47 \%$ of all liver cancers in SSA are attributable to Hepatitis infections while a significant proportion of the remainder are due to alcohol consumption (41). The predominance of liver cancers in men is thought to be due to the higher rate of risk factors including viral hepatitis, cigarette smoking, and alcohol consumption in men than in women (37).

Breast cancer is the most common cancer among Nigerian women and the second most common cancer in SSA (7). Risk factors, including age, sex, early age at menarche, parity, breast feeding, use of combined oral contraceptive pills, family history, diet, height, truncal obesity, and postmenopausal weight gain are responsible for most of the risk associated with breast cancer $(42,43)$. However, because of its high incidence, breast cancer was the most common alcohol associated cancer in this study. Nevertheless, the proportion of breast cancers attributable to alcohol consumption was low compared with the total number of breast cancer cases reported by the registries. Traditionally, alcohol consumption is less common among women in SSA however, with the increasing influence of western culture and lifestyles, more women are now getting exposed to alcohol, which may increase the risk of breast cancer in this population in the future $(44,45)$.

In contrast to the increased risk of the several cancers with alcohol consumption, the risk of thyroid cancer decreases with light and moderate alcohol intake $(8,18,46)$. Alcohol intake may have a protective effect on developing thyroid cancer by decreased levels of thyroid-stimulating hormone, the growth factor associated with thyroid cancer (47). Another potential biological mechanism is that alcohol may have a direct toxic effect on thyroid cells and reduce thyroid volume, which might lead to a decreased risk of thyroid cancer (48).

In general, while there are many publications on the association between alcohol intake and cancers, most of the studies have not focused carefully on the relationship with the amount consumed and the duration of consumption. Thus, although associations between several cancers and high alcohol intake is known, these associations become less clear for low to moderate intake of alcohol (49). Few countries in Africa have policies regulating alcohol consumption (19). Public health interventions

\section{REFERENCES}

1. Baan R, Straif K, Grosse Y, Secretan B, El Ghissassi F, Bouvard V, et al. Carcinogenicity of alcoholic beverages. Lancet Oncol (2007) 8(4):292-3. doi:10.1016/S1470-2045(07)70099-2

2. World Health Organization. Global Status Report on Alcohol and Health. Geneva, Switzerland: World Health Organization (2014).

3. Rethinking Drinking. (2016). Available from: https://www.rethinkingdrinking. niaaa.nih.gov/How-much-is-too-much/What-counts-as-a-drink/Whats-AStandard-Drink.aspx on the risks or benefits of alcohol intake need to be based on high quality data about its impact on diseases.

The limitations of our study include our inability to rule out incompleteness of cancer registration and underreporting of some alcohol associated cancers such as cancers of the liver, colon, and rectum due to lack of awareness, lack of presentation in hospitals, and inability to biopsy certain cancers due to limited facilities for accurate diagnosis. However, our sensitivity analyses show that our findings are similar to estimates for alcohol associated cancers in Nigeria as reported in the GLOBOCAN 2012 database of the IARC. Our results may be conservative estimates of the total burden of alcohol associated cancers in Nigeria given that we have restricted our analysis to cancers with an established association with alcohol drinking and excluded other cancers for which there is a less clear relationship such as lung and kidney cancers.

\section{CONCLUSION}

We present the first study conducted on the burden of alcohol associated cancers and the proportion attributable to alcohol consumption in the Nigerian population. This study sets the foundation for future studies in this field to document secular trends and enable appropriate public health interventions.

\section{AUTHOR CONTRIBUTIONS}

MO and EJ-A contributed to data collection, data analyses, and drafting the manuscript. All authors contributed to the writing of this manuscript. ED and SA contributed to data interpretation and revising it critically for intellectual content. EO, FI, TO, EE, and $\mathrm{RH}$ contributed to data collection and data quality. CA conceived the idea for the study, obtained funding, provided critical revisions, and guided all aspects of the paper. All authors read and approved the final manuscript.

\section{ACKNOWLEDGMENTS}

We acknowledge the staff of Abuja and Enugu population-based cancer registries for their work in data collection and entry. This work was supported by IHV-UM Capacity Development for Research into AIDS-Associated Malignancies (CADRE, NIH/ NCI D43CA153792) and the African Collaborative Center for Microbiome and Genomics Research (ACCME, NIH/NHGRI U54HG006947). The content is solely the responsibility of the authors and does not necessarily represent the official views of the National Cancer Institute, or the National Institutes of Health.

4. Praud D, Rota M, Rehm J, Shield K, Zatoński W, Hashibe M, et al. Cancer incidence and mortality attributable to alcohol consumption. Int J Cancer (2016) 138:1380-7. doi:10.1002/ijc.29890

5. Alavanja M, Bartsch H, Allen N, Bhisey R, Buffler P, Friborg J, et al. International Agency for Research on Cancer Monographs on Evaluation of Carcinogenic Risks to Human 100E: Alcohol Drinking. Lyon, France: International Agency for Research on Cancer (2012).

6. World Cancer Research Fund and American Institute for Cancer Research. Food, Nutrition, Physical Activity, and the Prevention of Cancer: A Global Perspective. Washington, DC: AICR (2007). 
7. Ferlay J, Soerjomataram I, Dikshit R, Eser S, Mathers C, Rebelo M, et al. Cancer incidence and mortality worldwide: sources, methods and major patterns in GLOBOCAN 2012. Int J Cancer (2015) 136(5):E359-86. doi:10.1002/ ijc. 29210

8. Wang X, Cheng W, Li J, Zhu J. A meta-analysis of alcohol consumption and thyroid cancer risk. Oncotarget (2016) 7(34):55912-23. doi:10.18632/ oncotarget. 10352

9. Liang H, Wang J, Xiao H, Wang D, Wei W, Qiao Y, et al. Estimation of cancer incidence and mortality attributable to alcohol drinking in China. BMC Public Health (2010) 10:730. doi:10.1186/1471-2458-10-730

10. Park S, Shin HR, Lee B, Shin A, Jung KW, Lee DH, et al. Attributable fraction of alcohol consumption on cancer using population-based nationwide cancer incidence and mortality data in the Republic of Korea. BMC Cancer (2014) 14:420. doi:10.1186/1471-2407-14-420

11. Pandeya N, Wilson LF, Webb PM, Neale RE, Bain CJ, Whiteman DC. Cancers in Australia in 2010 attributable to the consumption of alcohol. Aust N Z J Public Health (2015) 39(5):408-13. doi:10.1111/1753-6405.12446

12. Nelson DE, Jarman DW, Rehm J, Greenfield TK, Rey G, Kerr WC, et al. Alcohol-attributable cancer deaths and years of potential life lost in the United States. Am J Public Health (2013) 103(4):641-8. doi:10.2105/AJPH.2012. 301199

13. Parkin DM. 3. Cancers attributable to consumption of alcohol in the UK in 2010. Br J Cancer (2011) 105(Suppl 2):S14-8. doi:10.1038/bjc.2011.475

14. Nigeria Population Census. (2017). Available from: http://nigeria.opendataforafrica.org/ifpbxbd/state-population-2006

15. Boffetta P, Hashibe M, La Vecchia C, Zatonski W, Rehm J. The burden of cancer attributable to alcohol drinking. Int J Cancer (2006) 119(4):884-7. doi:10.1002/ijc. 21903

16. International Agency for Research on Cancer. GLOBOCAN 2012. Lyon: IARC Cancer Base (2016). Available from: http://globocan.iarc.fr/Pages/ fact_sheets_population.aspx

17. National Health Research Ethics Committee of Nigeria, National Code for Health Research Ethics. National Health Research Ethics Committee of Nigeria. Abuja: Federal Ministry of Health of Nigeria (2007).

18. Hong SH, Myung SK, Kim HS; The Korean Meta-Analysis (KORMA) Study Group. Alcohol Intake and Risk of Thyroid Cancer: A Meta-Analysis of Observational Studies. Cancer Res Treat (2016).

19. Dumbili E. Changing patterns of alcohol consumption in nigeria: an exploration of responsible factors and consequences. Med Soc (2013) 7(1):20-33.

20. Hashibe M, Brennan P, Chuang SC, Boccia S, Castellsague X, Chen C, et al. Interaction between tobacco and alcohol use and the risk of head and neck cancer: pooled analysis in the international head and neck cancer epidemiology consortium. Cancer Epidemiol Biomarkers Prev (2009) 18(2):541-50. doi:10.1158/1055-9965.EPI-08-0347

21. Chattopadhyay A, Weatherspoon D, Pinto A. Human papillomavirus and oral cancer: a primer for dental public health professionals. Community Dent Health (2015) 32(2):117-28. doi:10.1922/CDH_3460Chattopadhyay12

22. McCormack VA, Menya D, Munishi MO, Dzamalala C, Gasmelseed N, Leon Roux M, et al. Informing etiologic research priorities for squamous cell esophageal cancer in Africa: a review of setting-specific exposures to known and putative risk factors. Int J Cancer (2017) 140(2):259-71. doi:10.1002/ ijc.30292

23. Walker AR, Adam F, Walker J, Walker BF. Cancer of the oesophagus in Africans in sub-Saharan Africa: any hopes for its control? Eur J Cancer Prev (2002) 11(5):413-8. doi:10.1097/00008469-200210000-00002

24. Oga EA, Schumaker LM, Alabi BS, Obaseki D, Umana A, Bassey IA, et al. Paucity of HPV-related head and neck cancers (HNC) in Nigeria. PLoS One (2016) 11(4):e0152828. doi:10.1371/journal.pone.0152828

25. Kachala R. Systematic review: epidemiology of oesophageal cancer in SubSaharan Africa. Malawi Med J (2010) 22(3):65-70. doi:10.4314/mmj. v22i3.62190

26. Baquet C, Commiskey P, Mack K, Meltzer S, Mishra SI. Esophageal cancer epidemiology in blacks and whites: racial and gender disparities in incidence, mortality, survival rates and histology. J Natl Med Assoc (2005) 97(11):1471-8.

27. Okello S, Churchill C, Owori R, Nasasira B, Tumuhimbise C, Abonga CL, et al. Population attributable fraction of esophageal squamous cell carcinoma due to smoking and alcohol in Uganda. BMC Cancer (2016) 16:446. doi:10.1186/ s12885-016-2492-x
28. Van Rensburg S. Epidemiologic and dietary evidence for a specific nutritional predisposition to oesophageal cancer. J Natl Cancer Inst (1981) 67:243-51.

29. Yang SJ, Yokoyama A, Yokoyama T, Huang YC, Wu SY, Shao Y, et al. Relationship between genetic polymorphisms of ALDH2 and ADH1B and esophageal cancer risk: a meta-analysis. World J Gastroenterol (2010) 16(33):4210-20. doi:10.3748/wjg.v16.i33.4210

30. Kang J. Systematic review: geographical and ethnic differences in gastrooesophageal reflux disease. Aliment Pharmacol Ther (2004) 20(7):705-17. doi:10.1111/j.1365-2036.2004.02165.x

31. Jedy-Agba E, Curado MP, Ogunbiyi O, Oga E, Fabowale T, Igbinoba F, et al. Cancer incidence in Nigeria: a report from population-based cancer registries. Cancer Epidemiol (2012) 36(5):e271-8. doi:10.1016/j.canep.2012.04.007

32. Douaiher J, Ravipati A, Grams B, Chowdhury S, Alatise O, Are C. Colorectal cancer-global burden, trends, and geographical variations. J Surg Oncol (2017) 115(5):619-30. doi:10.1002/jso.24578

33. Graham A, Adeloye D, Grant L, Theodoratou E, Campbell H. Estimating the incidence of colorectal cancer in Sub-Saharan Africa: a systematic analysis. J Glob Health (2012) 2(2):020404. doi:10.7189/jogh.02.020404

34. Irabor D. Diet, environmental factors and increasing incidence of colorectal cancer in Nigeria. Ann Nig Med (2016) 8(2):58-64. doi:10.4103/0331-3131. 153353

35. Gong J, Hutter CM, Newcomb PA, Ulrich CM, Bien SA, Campbell PT, et al. Genome-wide interaction analyses between genetic variants and alcohol consumption and smoking for risk of colorectal cancer. PLoS Genet (2016) 12(10):e1006296. doi:10.1371/journal.pgen.1006296

36. Oyesanmi O, Snyder D, Sullivan N, Reston J, Treadwell J, Schoelles KM. Alcohol consumption and cancer risk: understanding possible causal mechanisms for breast and colorectal cancers. Evid Rep Technol Assess (Full Rep) (2010) 197:1-151.

37. Tognarelli J, Ladep NG, Crossey MM, Okeke E, Duguru M, Banwat E, et al. Reasons why West Africa continues to be a hotbed for hepatocellular carcinoma. Niger Med J (2015) 56(4):231-5. doi:10.4103/0300-1652.165032

38. Sighoko D, Curado MP, Bourgeois D, Mendy M, Hainaut P, Bah E. Increase in female liver cancer in the Gambia, West Africa: evidence from 19 years of population-based cancer registration (1988-2006). PLoS One (2011) 6(4):e18415. doi:10.1371/journal.pone.0018415

39. Nwokediuko SC, Osuala PC, Uduma UV, Alaneme AK, Onwuka CC, Mesigo C. Pattern of liver disease admissions in a Nigerian tertiary hospital. Niger J Clin Pract (2013) 16(3):339-42. doi:10.4103/1119-3077.113458

40. Odutola M, Jedy-Agba EE, Dareng EO, Oga EA, Igbinoba F, Otu T, et al. Burden of cancers attributable to infectious agents in Nigeria: 2012-2014. Front Oncol (2016) 6:216. doi:10.3389/fonc.2016.00216

41. Musa BM, Bussell S, Borodo MM, Samaila AA, Femi OL. Prevalence of hepatitis B virus infection in Nigeria, 2000-2013: a systematic review and meta-analysis. Niger JClin Pract (2015) 18(2):163-72. doi:10.4103/1119-3077.151035

42. Helmrich SP, Shapiro S, Rosenberg L, Kaufman DW, Slone D, Bain C, et al. Risk factors for breast cancer. Am J Epidemiol (1983) 117(1):35-45. doi:10.1093/ oxfordjournals.aje.a113513

43. Akarolo-Anthony SN, Ogundiran TO, Adebamowo CA. Emerging breast cancer epidemic: evidence from Africa. Breast Cancer Res (2010) 12(Suppl 4): S8. doi:10.1186/bcr2737

44. Qian F, Ogundiran T, Hou N, Ndom P, Gakwaya A, Jombwe J, et al. Alcohol consumption and breast cancer risk among women in three sub-Saharan African countries. PLoS One (2014) 9(9):e106908. doi:10.1371/journal. pone. 0106908

45. Adebamowo CA, Adekunle OO. Case-controlled study of the epidemiological risk factors for breast cancer in Nigeria. Br J Surg (1999) 86(5):665-8. doi:10.1046/j.1365-2168.1999.01117.x

46. Hwang Y, Lee KE, Weiderpass E, Park YJ, Chai YJ, Kwon H, et al. Acute high-dose and chronic lifetime exposure to alcohol consumption and differentiated thyroid cancer: T-CALOS Korea. PLoS One (2016) 11(3):e0151562. doi:10.1371/journal.pone.0151562

47. Boelaert K. The association between serum TSH concentration and thyroid cancer. Endocr Relat Cancer (2009) 16:1065-72. doi:10.1677/ERC-09-0150

48. Dal Maso L, Bosetti C, La Vecchia C, Franceschi S. Risk factors for thyroid cancer: an epidemiological review focused on nutritional factors. Cancer Causes Control (2009) 20(1):75-86. doi:10.1007/s10552-008-9219-5 
49. Mukamal KJ, Clowry CM, Murray MM, Hendriks HF, Rimm EB, Sink KM, et al. Moderate alcohol consumption and chronic disease: the case for a longterm trial. Alcohol Clin Exp Res (2016) 40(11):2283-91. doi:10.1111/acer.13231

Conflict of Interest Statement: The authors declare that the research was conducted in the absence of any commercial or financial relationships that could be construed as a potential conflict of interest.
Copyright (C) 2017 Odutola, Jedy-Agba, Dareng, Adebamowo, Oga, Igbinoba, Otu, Ezeome, Hassan and Adebamowo. This is an open-access article distributed under the terms of the Creative Commons Attribution License (CC BY). The use, distribution or reproduction in other forums is permitted, provided the original author(s) or licensor are credited and that the original publication in this journal is cited, in accordance with accepted academic practice. No use, distribution or reproduction is permitted which does not comply with these terms. 